\title{
Cruz Vinto desde la superficie: alcances y limitaciones de la sintaxis espacial en un sitio del Periodo de Desarrollos Regionales Tardío (ca. 1200 - 1450 d.C.) en el Norte de Lípez, Potosí, Bolivia
}

\author{
José María VAQUER \\ CONICET - Instituto de Arqueología, Universidad de Buenos Aires \\ jmvaquer@yahoo.com \\ Axel Emil NIELSEN \\ CONICET - Instituto Nacional de Antropología y Pensamiento Latinoamericano (Argentina) \\ axelnielsen@gmail.com
}

Recibido: 25 de marzo de 2010

Aceptado: 26 de febrero de 2011

\begin{abstract}
RESUMEN
En este trabajo presentamos los resultados de dos instancias metodológicas orientadas a maximizar la información de superficie: el análisis de planos y el relevamiento del material superficial. Esta metodología se utilizó con el objetivo de interpretar la estructuración de los espacios externos vinculados con actividades domésticas en Cruz Vinto, un asentamiento del Periodo de Desarrollos Regionales Tardío (1200-1450 d.C.) en el Norte de Lípez, Potosí, Bolivia. Los resultados obtenidos apuntan a que la sintaxis espacial debe ser utilizada como una instancia metodológica y no como un fin en sí mismo, ya que el modelo planteado no fue congruente con los resultados obtenidos en el relevamiento del material superficial, pero de todas formas constituye una herramienta válida para generar interpretaciones que posteriormente deben ser complementadas con otras líneas de evidencia.
\end{abstract}

Palabras clave: Estructuración del espacio; sintaxis espacial; relevamiento del material superficial.

Cruz Vinto from the Surface: Reach and Limitations of Space Syntax in a Settlement from Late Regional Developments Period (ca 1200-1450 AD) in Northern Lipez, Potosí, Bolivia

\begin{abstract}
In this paper we present the results of two methodological steps oriented to maximize data from surface: plan analysis and the survey of surface materials. This methodology was applied to interpret the structuration of external spaces related with domestic activities in Cruz Vinto, a settlement from the Late Regional Development Period (1200-1450 AD) in Northern Lípez, Potosí, Bolivia. The results obtained made us consider space syntax as a methodological instance and not an end in itself. The model proposed from space syntax was not coherent with the distribution of surface materials. Nevertheless, it constitutes a valid tool for generating interpretations that must be intertwined with other lines of evidence.
\end{abstract}

Keywords: Space structuration, space syntax, surface material survey.

Sumario: 1. Introducción. 2. Metodología. 3. Desarrollo. 4. Discusión. 5. Conclusiones. 6. Referencias bibliográficas. 


\section{Introducción}

Las sociedades tardías del Norte de Lípez (Potosí, Bolivia) se han caracterizado como sociedades con una fuerte orientación corporativa, en las que los grupos funcionaban como unidad de apropiación de recursos (Nielsen 2001, 2002, 2006). Entendiendo «lo corporativo» como un conjunto de prácticas orientadas a crear una subjetividad que sobrepasa la noción de individuo como sujeto único de la práctica, este trabajo pretende explorar las materialidades que, por un lado, son el producto de las prácticas corporativas $y$, por otro, las reproducen de manera recurrente.

Para ello, entendemos que las prácticas sociales se hallan fuertemente vinculadas con el escenario en el cual tienen lugar, hasta el punto de que el escenario se transforma en una condición necesaria para la significación de las mismas (Ingold 2000; Thomas 1996). Los agentes sociales experimentan el espacio corporalmente de manera no discursiva, por lo que algunos significados asociados al mismo se encuentran incorporados de manera casi inconsciente (Bourdieu 1977, 1999a, 1999b). En este proceso de incorporación también es fundamental la cotidianeidad con que los agentes experimentan el espacio y se involucran en actividades que, en el ámbito doméstico, se repiten diariamente. De esta manera, la estructuración del espacio se convierte en uno de los locus principales en la producción y reproducción de estructuras sociales. También cabe mencionar la importancia de este proceso corporal en el disciplinamiento de los agentes sociales (Foucault 1975).

En este sentido, consideramos que en la estructuración del espacio y las actividades es donde deben buscarse los principios que estructuran las prácticas que resultan en la construcción y reproducción de sujetos corporativos. Para ello, analizamos en Cruz Vinto (Península de Colcha K, Norte de Lípez) (Nielsen 2001, 2002; Vaquer 2009) los espacios exteriores relacionados con las estructuras domésticas, es decir, en aquellos espacios externos donde se realizaron actividades domésticas.

En esta ocasión presentamos, comparamos, interpretamos y discutimos los resultados de dos instancias metodológicas vinculadas con la cultura material superficial: el análisis sintáctico de los planos del asentamiento y los resultados de un relevamiento completo del material superficial. Los resultados del análisis sintáctico son coherentes con materialidades estructuradas alrededor de la incorporación de un habitus corporativo, aunque los mismos deben ser tomados como preliminares al tratarse exclusivamente de interpretaciones desarrolladas a partir de material superficial. Con respecto a la distribución del material superficial, no hubo coherencia con los datos obtenidos en la sintaxis, lo cual debe tomarse como una llamada de atención acerca de las posibilidades interpretativas de los análisis formales.

\subsection{Consideraciones teóricas}

Según Bourdieu (1977), cuando no existe una institucionalización de la educación como una práctica autónoma, el grupo y un ambiente simbólicamente estructurado ejercen una acción pedagógica anónima. Esta transmisión se produce a través de la práctica, en un estado práctico que no alcanza el nivel del discurso. La hexis corporal 
(Bourdieu 1977, 1999b) se comunica directamente con las funciones motoras, en forma de patrones de posturas y gestos individuales y sistemáticos que implican un sistema de técnicas que involucran al cuerpo y a las herramientas, que se encuentra cargado de valores y significados sociales. Este aprendizaje se produce a través de la aplicación de principios coherentes en la práctica en ámbitos y productos sociales como los proverbios, los dichos, las máximas, las canciones, las adivinanzas y los juegos; en los objetos como las herramientas, la casa o el asentamiento.

Para la teoría de la práctica de Bourdieu, la casa cumple un rol principal, ya que es lugar donde se transmiten en forma práctica los esquemas constitutivos del habitus. El concepto de incorporación se relaciona con esta forma de aprendizaje con el cuerpo, a través de habitar el espacio doméstico. Todas las acciones llevadas a cabo en la casa son una suerte de «ejercicios estructurales» (Bourdieu 1977) a través de los cuales se construye un manejo práctico de los esquemas fundamentales que organizan las prácticas y las representaciones. Las manipulaciones simbólicas de la experiencia corporal, a través del tránsito en un espacio estructurado de acuerdo con principios mitológicos y los movimientos asociados, tienden a imponer la integración del espacio corporal con el espacio cósmico al proponer en los mismos conceptos la relación entre el hombre y el mundo natural, y los estados y acciones opuestos y complementarios de los sexos. En este sentido, la oposición entre los roles del hombre y la mujer articulan y configuran toda una serie de oposiciones conceptuales que son reveladas en la práctica (Bourdieu 1977, 2000).

Es necesario enfatizar que la operación de estos esquemas se da en el ámbito de la práctica; y es a partir de la objetivación de las prácticas y experiencias pasadas que se construyen representaciones culturales de las mismas. Bourdieu propone la existencia de un «lógica práctica» que articula a las mismas a partir de los esquemas generativos del habitus.

\subsection{La zona de estudio y su historia cultural}

La zona de estudio se encuentra ubicada en el Norte de Lípez, Departamento de Potosí, Bolivia (Figura 1). Es un área de forma triangular delimitada por el Salar de Uyuni, el Río Grande de Lípez y la cota de los $4500 \mathrm{~m}$ de la Cordillera Occidental. Esta región habría servido en épocas prehispánicas tardías como frontera social y cultural y como motor de tráfico caravanero entre las regiones que la circundan (Nielsen et al. 1999). A su vez, el sector norte fue el ámbito de dispersión del «Señorío Mallku» durante el Periodo de Desarrollos Regionales (900 - 1450 d.C.) o Periodo Intermedio Tardío en la periodización de la región Andina (Arellano y Berberián 1981).

A pesar de que el área de estudio se encuentra ubicada en una zona nodal con respecto a la articulación de la región Andes sur, no fue objeto de investigaciones arqueológicas intensivas hasta hace relativamente poco. Una excepción a esta tendencia la representa el trabajo de Arellano y Berberián (1981), quienes visitaron la región y definieron, basándose en la cerámica y en el patrón funerario, la existencia de un señorío aymara post-Tiwanaku denominado «señorío Mallku» entre el 900 y el 1450 d.C. 


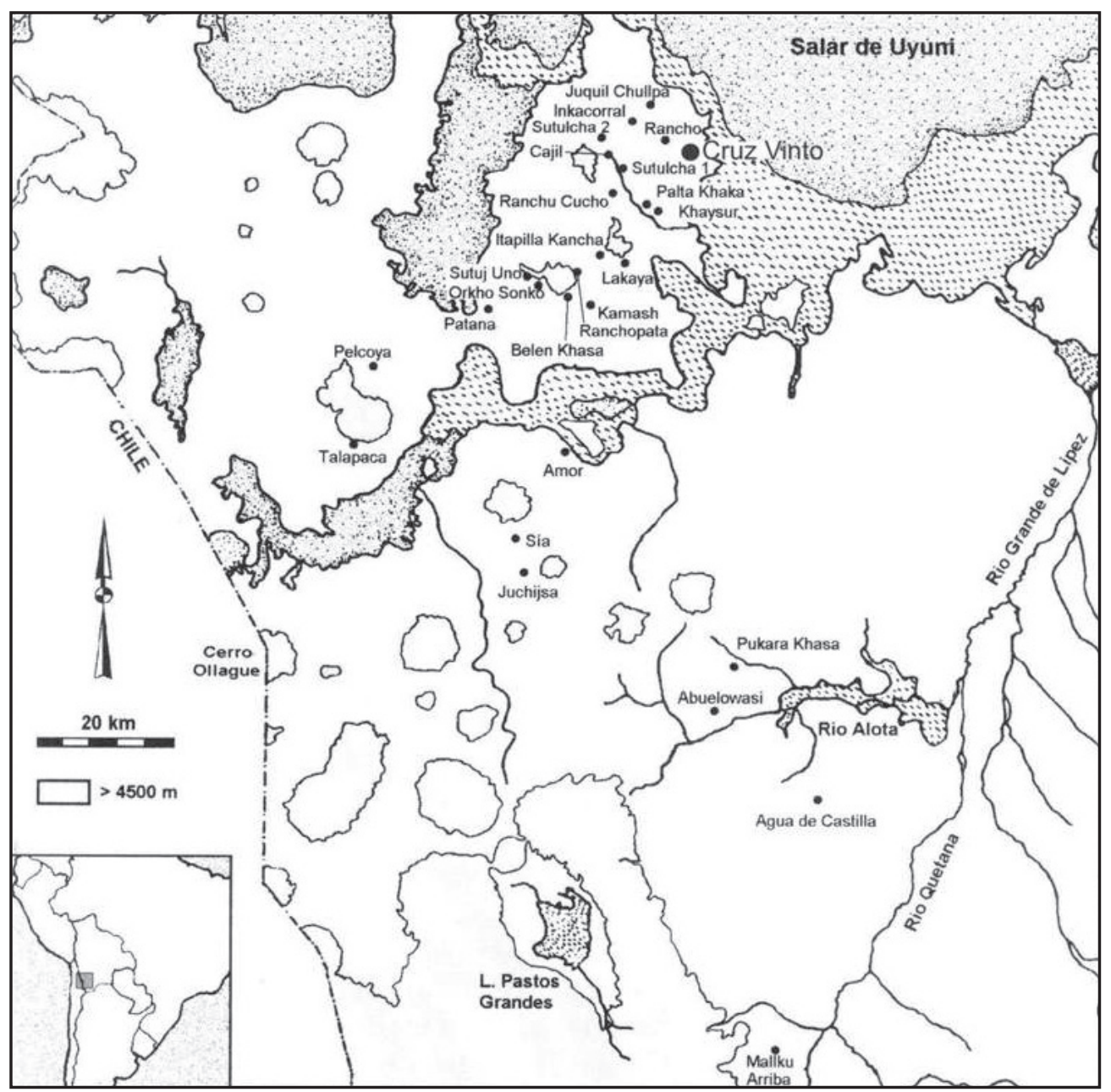

Figura 1: Mapa del Norte de Lípez mostrando la ubicación de Cruz Vinto y otros sitios arqueológicos de la región. Modificado a partir de Nielsen (2000).

Posteriormente, Nielsen propone una primera distinción entre la región del Norte de Lípez, con una fuerte presencia de elementos vinculados al «señorío Mallku» (cerámica de estilo Mallku / Hedionda, asentamientos fortificados o pukaras, chullpas), sociedades sedentarias con una base agrícola, y la región del Sur de Lípez, con preeminencia de asentamientos vinculados a la actividad caravanera o jaras que se relacionarían con una ocupación por parte de sociedades pastoriles. Esta distinción de los diferentes sistemas sociales que ocuparon la zona estaría determinada por las posibilidades que brinda el ambiente. La zona Norte de Lípez, ubicada en la margen sur del Salar de Uyuni, es una región con mayor humedad y temperaturas moderadas que brinda un ambiente donde es posible el cultivo de especies microtérmicas como 


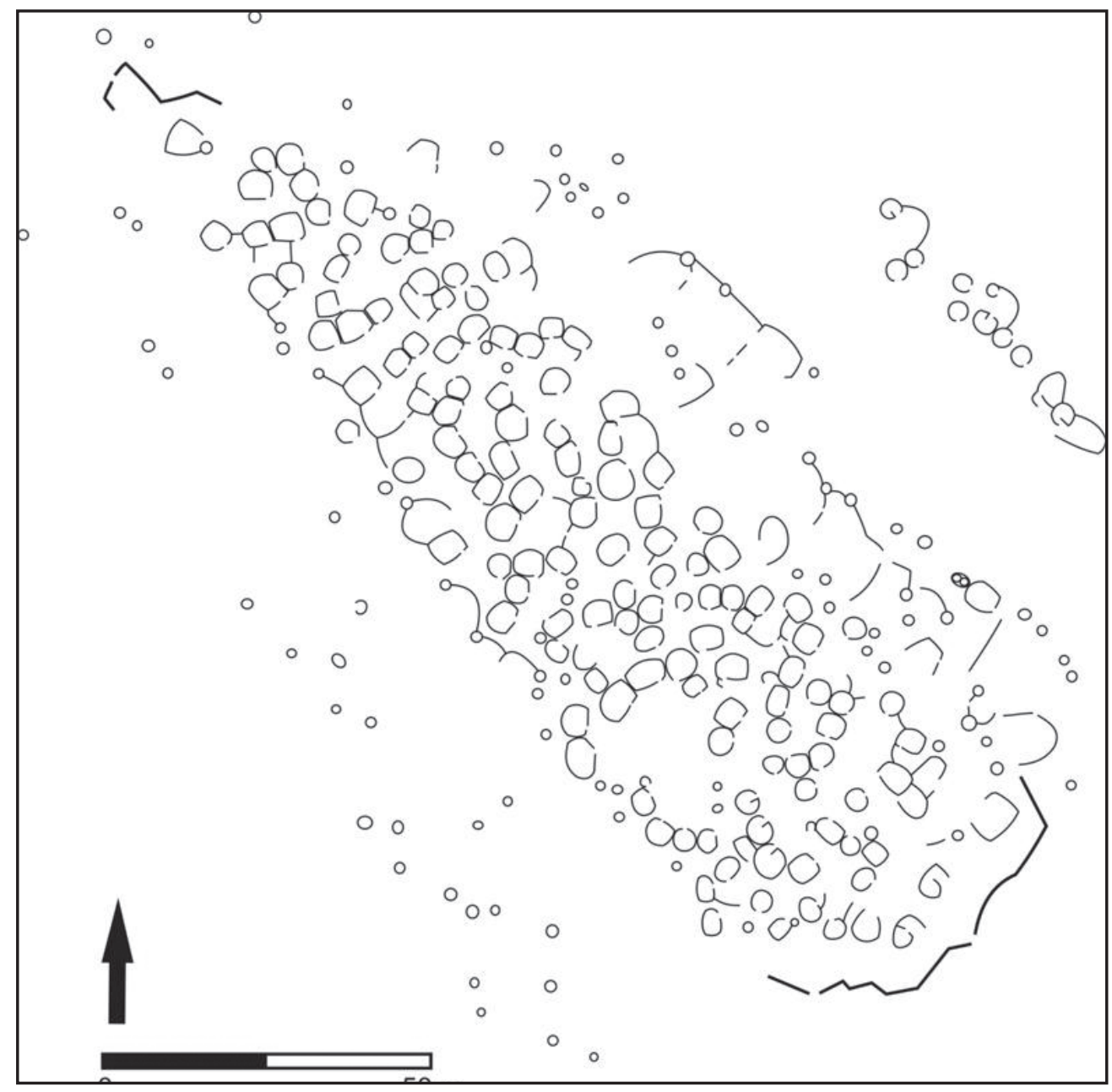

Figura 2: Plano de Cruz Vinto.

la quinua y la papa, junto con la presencia de vegas o bofedales para el forrajeo de animales (Nielsen 1998, 2000, 2001; Nielsen et al 1999).

\subsection{Cruz Vinto}

Dentro de la clasificación propuesta por Nielsen (2001), Cruz Vinto es un poblado defensivo o pukara que combina recintos circulares / elípticos y rectangulares (Figura 2). Está emplazado en una meseta rodeada de acantilados rocosos que se eleva aproximadamente $100 \mathrm{~m}$ sobre el terreno que lo circunda. Esta localización defensiva determina que solamente se puede acceder al asentamiento por los extremos noroeste 
Cuadro 1: Dataciones radiocarbónicas de Cruz Vinto (modificado de Nielsen 2002)

\begin{tabular}{lllll}
\hline \multicolumn{1}{c}{ Procedencia } & C14 AP & \multicolumn{1}{c}{ C14 Cal } & Cal AD 68\% & Cal AD 95\% \\
\hline Cruz Vinto & $570 \pm 70$ & $1334,1336,1400$ & $1302-1426$ & $1286-1445$ \\
Cruz Vinto Recinto 1 & $780 \pm 70$ & 1263 & $1211-1287$ & $1059-1382$ \\
Cruz Vinto Recinto 2 & $590 \pm 60$ & $1329,1343,1495$ & $1300-1413$ & $1268-1437$ \\
Cruz Vinto & $600 \pm 40$ & & $1306-1363$ & $1294-1411$ \\
Base UMD 83 & & & $1385-1400$ & \\
\hline
\end{tabular}

y suroeste de la meseta, los cuales se encuentran protegidos por murallas con accesos definidos y vanos semejantes a troneras (Nielsen 2002).

La arquitectura se encuentra emplazada en dos terrazas determinadas por la topografía. La primera de ellas presenta principalmente torres-chullpas (torres funerarias de piedra con planta circular o rectangular, de 1,20 $\mathrm{m}$ de alto con techo en falsa bóveda y una abertura en uno de sus lados) un muro defensivo y recintos de gran tamaño, posiblemente sin techar. Sobre el margen oeste de la misma localizamos una cantera de andesita, de donde se extrajeron los bloques para la construcción.

La segunda terraza es la que presenta la ocupación más densa, compuesta por recintos de planta circular, elíptica y rectangular. Relevamos 140 recintos que pueden presentarse aislados o en grupos de hasta seis unidades y un espacio central a modo de plaza. En las dos terrazas, y en el terreno circundante de la meseta relevamos 101 torres-chullpa (Vaquer 2009; Vaquer et al. 2010).

Una de las características que llaman la atención de este asentamiento es que se trata de un pukara sin asociación próxima a poblados bajos, modalidad principal del asentamiento de la región para este periodo (Nielsen 2001, 2002).

Obtuvimos cuatro fechados radiocarbónicos que ubican el lapso de ubicación de este sitio en el denominado Periodo de Desarrollos Regionales Tardío (1200-1430 d.C.) o Periodo Intermedio Tardío en la cronología de la región Andina (Cuadro 1).

\section{Metodología}

\subsection{Sintaxis espacial}

Hillier y Hanson (1984) postulan que los edificios crean un orden a partir de volúmenes vacíos de espacio. Es en ese ordenamiento del espacio donde se evidencia el propósito de construir, no en el producto físico resultante. Dicho orden espacial se trata realmente del orden de las relaciones entre las personas. El ordenamiento espacial de una sociedad es una de las formas más notorias de reconocer diferencias culturales entre formaciones sociales, es decir, las diferentes maneras en que los miembros de las sociedades experimentan y reproducen su existencia social. La sintaxis es la consistencia en la recuperación de las descripciones y la materialización de un momento al otro. 
El objetivo de los autores es descubrir qué tipo de restricciones al azar generan la familia de patrones que se reconocen en la forma de los asentamientos humanos (Hillier y Hanson 1984). Para lograr dicho objetivo, proponen dos instancias: el análisis de la disposición de los asentamientos y de los edificios. Parten de un modelo que conceptualiza a los asentamientos como el agregado al azar de celdas con una apertura en uno de sus lados, dada la condición de que las celdas se agregan en los lados y no en los vértices, y que el lado abierto permanezca libre. Este proceso generativo resulta en varias combinaciones posibles, de las cuales se pueden extraer las siguientes propiedades que a su vez pueden ser aplicadas al analizar asentamientos humanos:

a) Simetría: la restricción al azar requiere que una celda A y una celda B se conviertan en vecinos contiguos. La relación de vecindad implica que la relación de A con B es la misma que B con A.

b) Distribución: La estructura global se crea a partir de la disposición de un número de celdas individuales iguales.

De la misma manera, estas propiedades presuponen también la existencia de sus opuestos:

c) Asimetría: esta relación está presente si la relación de A con $\mathrm{B}$ no es la misma que la de B con A, por ejemplo si la celda A contuviera en su interior a la celda B.

d) No distribución: la estructura global está determinada por una sola celda, en vez de por varias. El caso expuesto anteriormente de una celda contenida dentro de la otra también es un ejemplo de no distribución.

Las celdas cerradas o abiertas están constituidas de dos tipos de material bruto: el espacio continuo y los elementos utilizados para crear límites que constituyen discontinuidades en el espacio. Un tercer elemento se reconoce: las entradas o comunicaciones, que se constituyen en mediadores entre el espacio exterior y el interior. El espacio interior se describe a partir de la configuración de los límites

Para lograr el análisis sintáctico de los asentamientos, Hillier y Hanson (1984) proponen una metodología llamada análisis alfa. Cualquier punto en la estructura espacial de un asentamiento puede ser visto como la intersección de dos líneas perpendiculares: una marcando la extensión global máxima o axial de ese punto en una línea recta; y la segunda representando la posición en un espacio convexo que representa la máxima extensión del punto en la segunda dimensión teniendo en cuenta la primera. Las diferencias entre estos sistemas espaciales representan las primeras diferencias en la extensión en una y dos dimensiones del sistema y la relación entre las mismas. Un mapa axial sería la expresión mínima de las líneas rectas que pasan a través de cada espacio convexo y determinan los vínculos axiales. A su vez, un mapa convexo sería la expresión mínima de los espacios convexos que cubren el sistema. Las estructuras espaciales urbanas pueden diferenciarse entre sí de acuerdo al grado de extensión axial y convexa de sus partes y de acuerdo a la relación entre ambas formas de extensión.

Una vez realizados los mapas axiales y convexos, Hillier y Hanson (1984) proponen una serie de índices para ser aplicados con el objetivo de dilucidar qué tipo de relaciones sociales estaría fomentando el uso del espacio. Para realizar el 
análisis alfa se consideran a cada uno de los espacios convexos como un nodo, y se representan como un punto. Las líneas representan las posibilidades de comunicación entre los nodos, de tal manera que al unir los puntos obtenemos los patrones de circulación del sitio.

\subsection{Relevamiento del material superficial}

El relevamiento del material superficial tuvo como objetivo evaluar la incidencia de los procesos de formación en la conformación del registro superficial, y relacionar la información obtenida en la primera etapa con el material de superficie para evaluar las categorías de «nodos» e «internodos» propuestas en el modelo de sintaxis espacial (ver más adelante) en términos de densidad de material superficial.

Para el trabajo de campo confeccionamos un grillado del asentamiento en unidades de $10 \mathrm{~m}$ por $10 \mathrm{~m}$ denominadas Unidades de Muestreo Dirigido (desde ahora UMD) (Berardi 2004). Las UMD son las unidades en las que se llevó a cabo el relevamiento. Se contabilizó y clasificó la totalidad del material presente en cada una de ellas (N =91), y también se llevó a cabo el relevamiento de variables relacionadas con los procesos de formación del registro.

También dentro de cada UMD se delimitaron Unidades de Procedencia (desde ahora UP), definidas por la microtopografía de cada UMD, por la presencia de concentraciones de material o por divisiones impuestas por la arquitectura. Se registraron todos los materiales presentes, se contaron la cantidad de fragmentos cerámicos, se los dividió por tamaño y estilo decorativo, y se registraron los artefactos líticos y los fragmentos óseos.

Como se mencionó anteriormente, dentro de cada UMD se analizaron una serie de variables relacionadas con el material superficial y los procesos de formación. Una vez procesada la información de cada una de las fichas en el laboratorio, se procedió a la confección de mapas temáticos que reflejan la incidencia de cada variable en la conformación del registro. Esta metodología permite una rápida apreciación de cada variable, ya que es un método gráfico que le asigna a cada valor una intensidad tonal dentro de un mismo color. Las variables analizadas fueron las superficies sedimentarias, la pendiente, la cobertura vegetal y la cantidad de material cerámico presente en cada UMD.

Las superficies sedimentarias fueron clasificadas de acuerdo con el tipo de clastos presente, ya que a partir de los ciclos de erosión y sedimentación es posible relacionar la abundancia de ciertos tipos de clastos con contextos pedogénicos específicos. Es esperable que sobre contextos de erosión permanezcan los clastos más grandes más resistentes a las acciones de gravedad y agua- mientras que en contextos de acumulación los clastos abundantes sean los de tamaño menor (arena, limo) más fáciles de ser transportados por ambos agentes (Berardi 2004). Para Cruz Vinto, definimos tres tipos de contextos sedimentarios: Acumulación, Erosión y Transición.

La pendiente fue relevada utilizando una escala cualitativa ordinal, relacionando el gradiente con las características de escurrimiento. Siguiendo la propuesta de Berardi 
Cuadro 2: Medidas de los fragmentos cerámicos (tomado de Berardi 2004)

\begin{tabular}{lcc}
\hline \multicolumn{1}{c}{ Tamaño } & Diámetro (en mm) & o (Phi) \\
\hline Muy pequeño & $=<16$ & -4 \\
Pequeño & $16-32$ & -5 \\
Mediano & $32-64$ & -6 \\
Grande & $64-128$ & -7 \\
Muy grande & $>=128$ & -8 \\
\hline
\end{tabular}

(2004), definimos cuatro tipos: Ausencia de Pendiente (escurrimiento lento), Suave a Moderada (escurrimiento lento a medio), Pronunciada (Escurrimiento rápido), y Barranca o Salto (caída).

Para la cobertura vegetal, utilizamos también una escala ordinal basada en el porcentaje de vegetación que cubría la superficie de las UMD. El resultado fueron cuatro categorías: Ausencia (entre 0 y 20\%), Baja (entre 20 y 40\%), Media (entre 40 y $60 \%$ ), Elevada (entre 60 y $80 \%$ ), y finalmente Muy Elevada (entre 80 y $100 \%$ ). Esta variable es importante porque se relaciona con la posibilidad de visibilidad de los materiales, y con la estabilidad de las superficies.

Otra variable registrada fue el tamaño de los fragmentos cerámicos. Si consideramos a los fragmentos como un tipo de clasto, el agrupamiento de éstos va a ser producto de los mismos factores que los suelos en general. Para evaluar esto último, medimos los tamaños de los fragmentos cerámicos en relación a una escala derivada del análisis sedimentológico, donde cada tamaño es el doble del siguiente en escala descendente (Berardi 2004). La escala utilizada fue la indicada en el Cuadro 2.

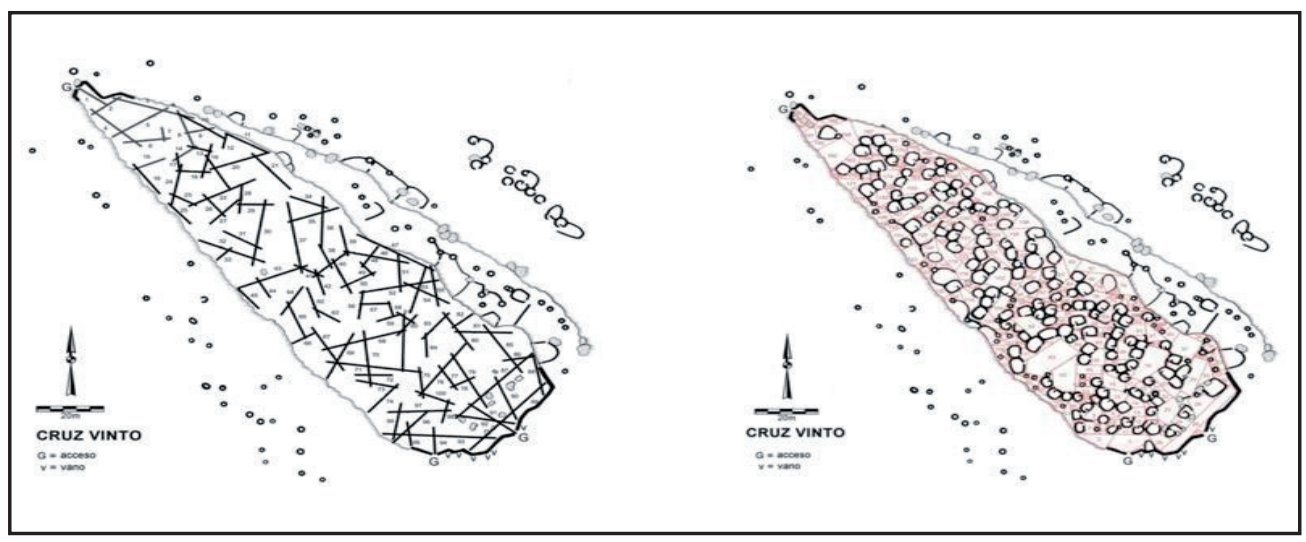

Figura 3: Mapa axial (izquierda) y convexo (derecha) de Cruz Vinto. 


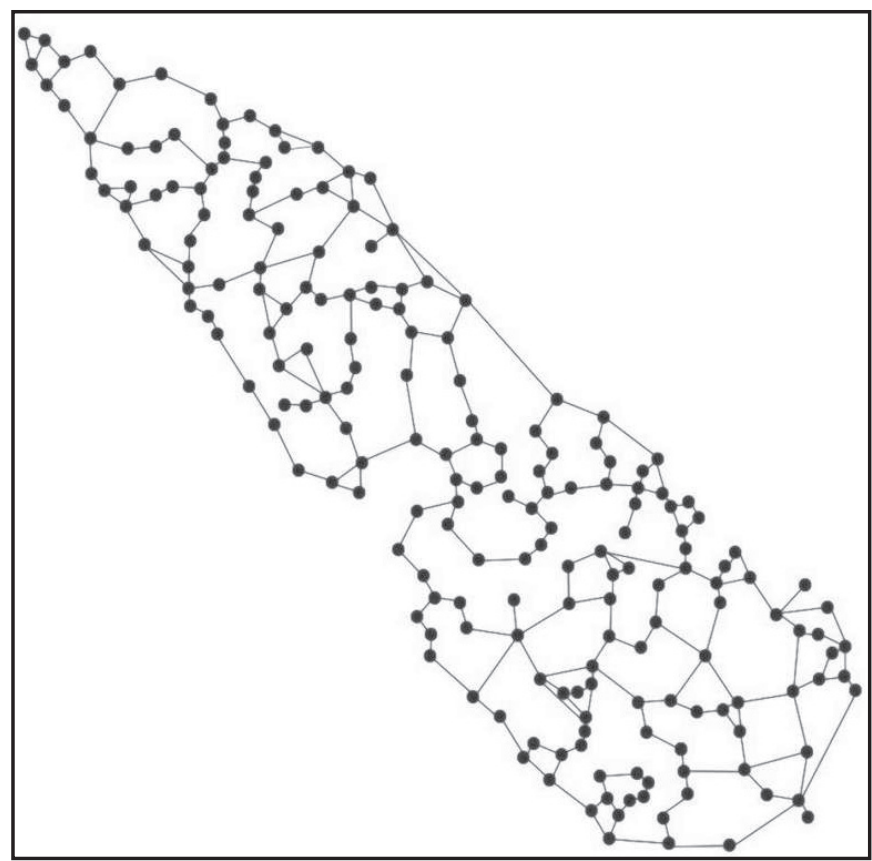

Figura 4: Espacios convexos de Cruz Vinto representados como puntos y su comunicación.

\section{Desarrollo}

\subsection{Sintaxis espacial de Cruz Vinto: el modelo}

Siguiendo la propuesta de Hillier y Hanson (1984), confeccionamos en primera instancia los mapas axiales y convexos de los espacios externos de Cruz Vinto (Figura 3). A partir de la confección de los mapas se obtuvieron un total de 199 espacios convexos y 100 líneas axiales

Luego consideramos cada espacio convexo como un punto, y se representaron mediante líneas las conexiones entre ellos (Figura 4). Esto permite visualizar gráficamente la relación entre el espacio axial y el espacio convexo.

En esta instancia ya es posible hacer una primera interpretación sintáctica del espacio de Cruz Vinto con relación a las propiedades de simetría y distribución propuestas por Hillier y Hanson (1984). Vemos en el gráfico que la mayoría de los espacios convexos se ordenan formando anillos, lo cual estaría remitiendo a un sistema distribuido asimétrico en la mayoría de los casos, y también existen algunos espacios ordenados de manera asimétrica (lineal). Esto implica cierta noción de profundidad en los espacios lo cual significa que para acceder a un punto determinado hay que pasar por otros.

Una vez establecidas las relaciones sintácticas del espacio, aplicamos dos índices propuestos por Hillier y Hanson (1984):

a) Índice de unión axial: representa la cantidad de espacios convexos que atraviesa cada línea axial extendida. Este número representa la cantidad de espacios 


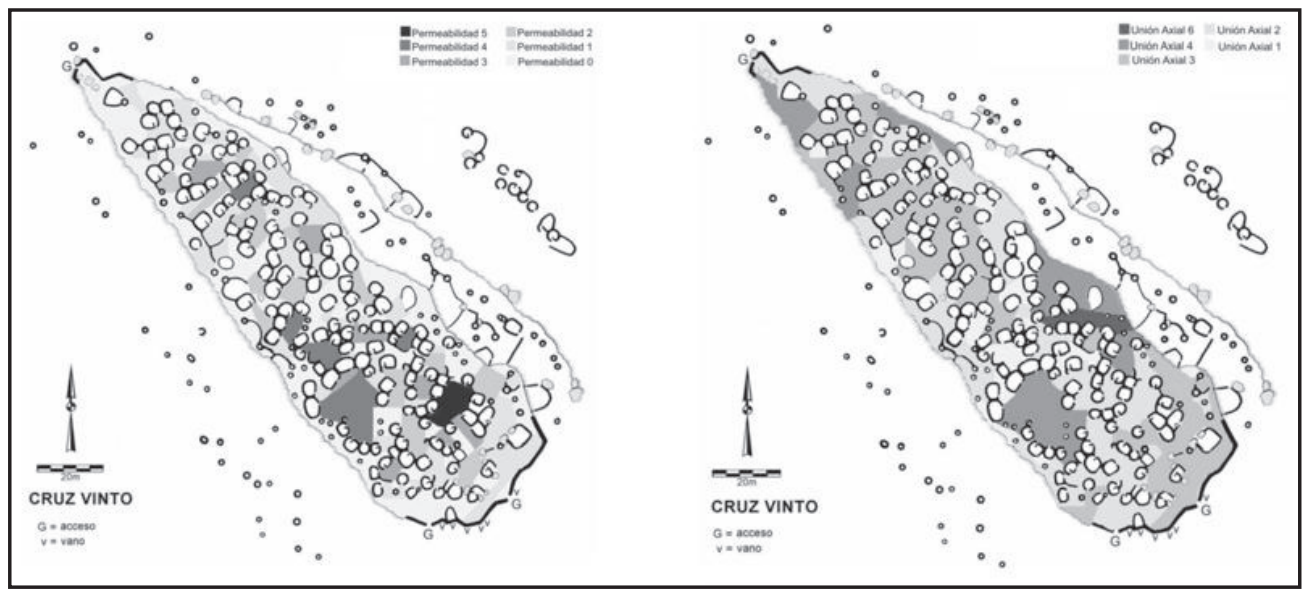

Figura 5: Mapas de Permeabilidad (izquierda) y Unión Axial (derecha).

convexos que uno puede percibir desde un punto determinado.

b) Índice espacio-edificios o permeabilidad: registra la cantidad de edificios que son adyacentes al espacio convexo; es decir, la permeabilidad.

A partir de los dos índices generamos expectativas que relacionan la sintaxis con el uso de los espacios exteriores (Vaquer 2009):

1) Los nodos van a ser espacios compartidos por varias unidades domésticas. Esto se expresa en un valor alto del índice espacio-edificio, es decir, una gran cantidad de recintos van a ser adyacentes y directamente permeables al mismo, y un bajo valor del índice de unión axial. A partir de la conformación de la muestra se estableció como valor alto que 3 o más recintos sean adyacentes al espacio convexo.

2) La función de nodo es excluyente de la circulación.

3) Los internodos son espacios de circulación. Esto se expresa en un valor alto del índice de unión axial, es decir, van a estar atravesados por líneas axiales que articulen varios espacios convexos y bajo valor de permeabilidad. Se definió como alto un valor de 3 o más, lo cual significa que se considera un internodo a aquellos espacios convexos que estén atravesados por líneas axiales que lo relacionen con por lo menos 2 espacios más. Estas líneas también se relacionan con la posibilidad de percepción de los espacios convexos desde un punto determinado -mayor cantidad de espacios convexos relacionados, mayor percepción-.

4) La función de internodo es excluyente de las actividades, o por lo menos a la realización de actividades que impliquen un bloqueo de la línea de circulación.

Una vez definidos estos conceptos operativos, generamos mapas temáticos donde la unión axial y la permeabilidad pueden apreciarse gráficamente (Figura 5).

Al hacer un análisis estadístico de correlación entre las variables de unión axial y de permeabilidad, se obtuvieron cuatro tipos de espacios convexos:

- Baja Permeabilidad, Alta Unión Axial (Internodos): Este tipo se encuentra representado por 105 espacios convexos, y son los espacios cuya función primaria 
fue la circulación y / o la realización de actividades que no impidan la circulación. Dentro de la muestra representa un 53\%, lo que estaría implicando dentro del modelo propuesto que un 53\% del espacio externo del asentamiento estaría destinado primariamente a circulación y articulación.

- Alta Permeabilidad, Baja Unión Axial (Nodos): Para este tipo se registraron 8 espacios convexos, es decir un $4 \%$ de la muestra. Según el modelo, estos espacios eran lugares de realización de actividades. La ubicación de los mismos es coherente con dicha función, ya que se localizan principalmente hacia el centro del asentamiento, a resguardo de los vientos y fuera de las vías de circulación principales.

- Baja Permeabilidad, Baja Unión Axial: Este tipo está representado por 78 casos, lo que equivale a un $39 \%$ de la muestra. Estos espacios se distribuyen por todo el asentamiento, y corresponderían a «espacios muertos», lugares que no se encuentran cruzados por líneas axiales ni tienen recintos permeables. Este tipo de espacios pueden responder a ambos tipos de funciones: circulación y articulación del espacio, o realización de actividades que pueden resultar molestas o incómodas de ser realizadas frente a las casas. En el caso de los espacios convexos ubicados en el margen este del asentamiento, son lugares excelentes para observar y controlar los movimientos en el Salar de Uyuni.

- Alta Permeabilidad, Alta Unión Axial: Esta categoría está representada por 8 espacios convexos y conforma el 4\%: restante de la muestra. Estos espacios son lugares que se articulan en líneas axiales y tienen varios recintos permeables. Según el modelo propuesto cumplirían ambas funciones. Es importante destacar que 3 de los espacios que conforman esta categoría pertenecen a la plaza del asentamiento, espacio que sin lugar a dudas tenía una funcionalidad especial dentro del mismo (Nielsen 2006).

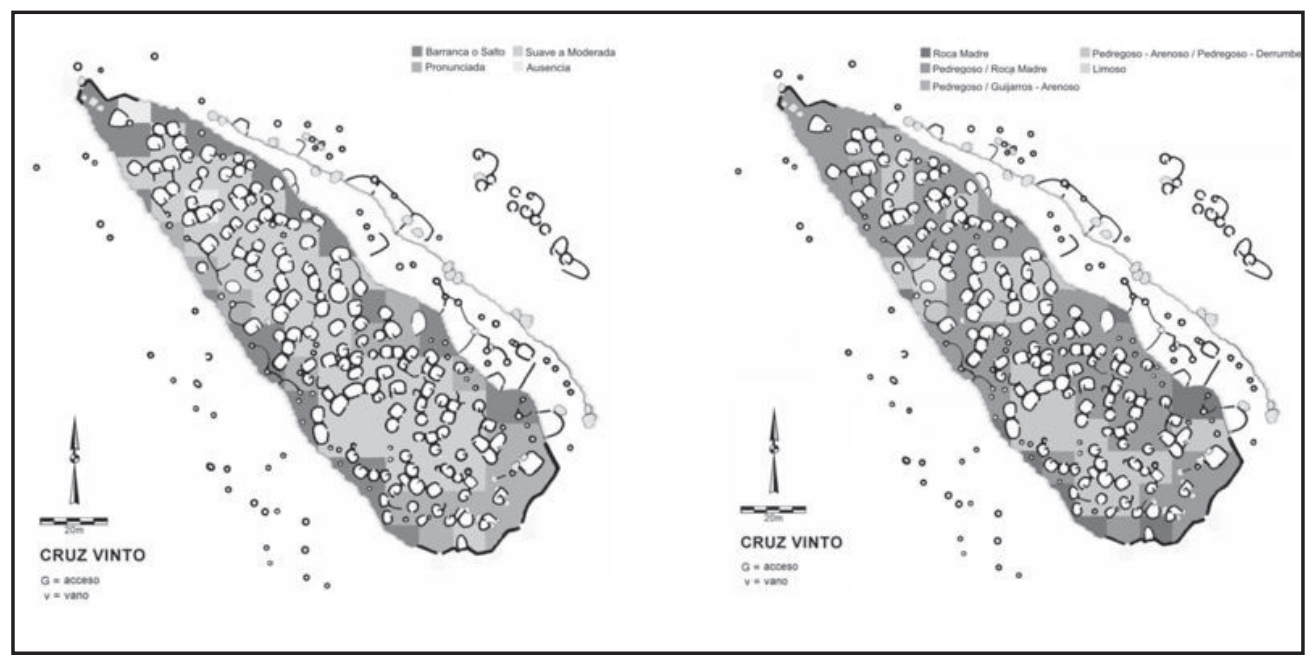

Figura 6: Mapas temáticos de Pendiente (izquierda) y Superficies Sedimentarias (derecha). 


\subsection{Material superficial}

Como se mencionó anteriormente, realizamos un relevamiento completo del material superficial, junto con variables relacionadas con la formación del registro. A partir de dicha información generamos una serie de mapas temáticos que permiten apreciar gráficamente el comportamiento espacial de las variables analizadas. Vamos a comenzar por el análisis de la pendiente y las superficies sedimentarias (Figura 6).

El tipo de pendiente más representado fue suave ( $86 \%$ de la muestra). En el gráfico apreciamos que los espacios convexos con menor pendiente se ubican hacia el centro de la meseta, mientras que en los bordes se encuentran pendientes más pronunciadas.

Con respecto a las superficies sedimentarias, la mayor parte se corresponde con contextos de erosión ( $76 \%$ de la muestra). Esto es coherente con un ambiente de puna, con lluvias estacionales intensas y la acción continua del viento. La ubicación del asentamiento en lo alto de la meseta determina que los suelos en general sean bastante pobres, con escasa potencia. Los contextos de depósito y transición se localizan principalmente en el sector sur del asentamiento, en UMD rodeados de arquitectura.

La cobertura vegetal está compuesta principalmente por t'olas (Parastrephia sp.) y cardones (Trichocerus pasacana) localizados principalmente sobre la barranca. Sobre las UMD analizadas, el $60 \%$ correspondió a cobertura vegetal baja y el $27 \%$ a cobertura vegetal media.

\subsection{La muestra cerámica}

En el relevamiento de superficie detectamos muy poca cantidad de material óseo y lítico, por lo que la interpretación se va a centrar en la distribución de la cerámica. La
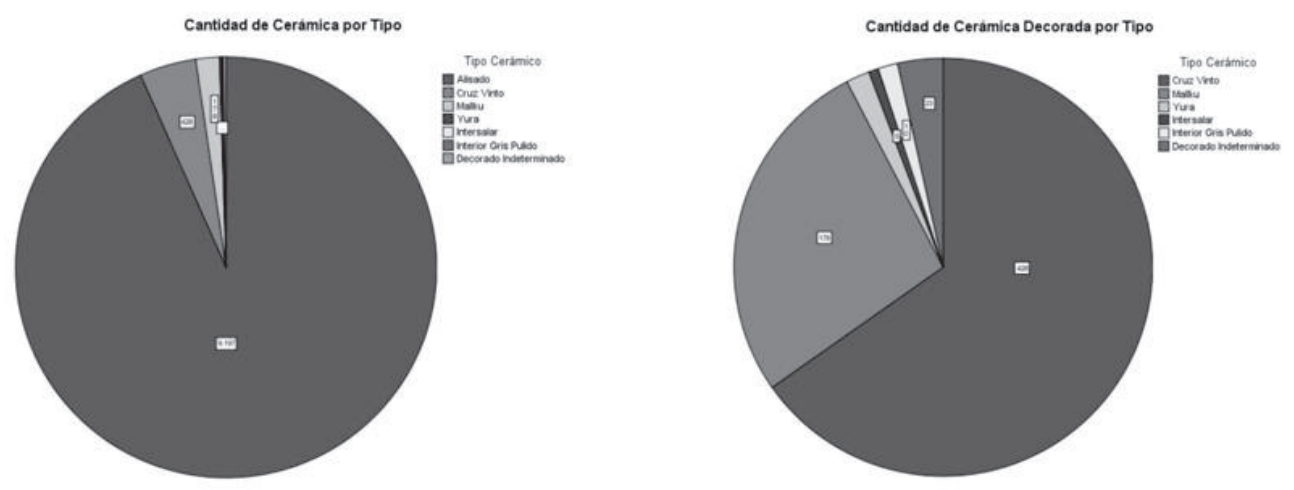

Figura 7: Cantidad de cerámica por tipo $(\mathrm{N}=9853)$ (izquierda) y cantidad de cerámica decorada por tipo $(\mathrm{N}=656)$ (derecha). 


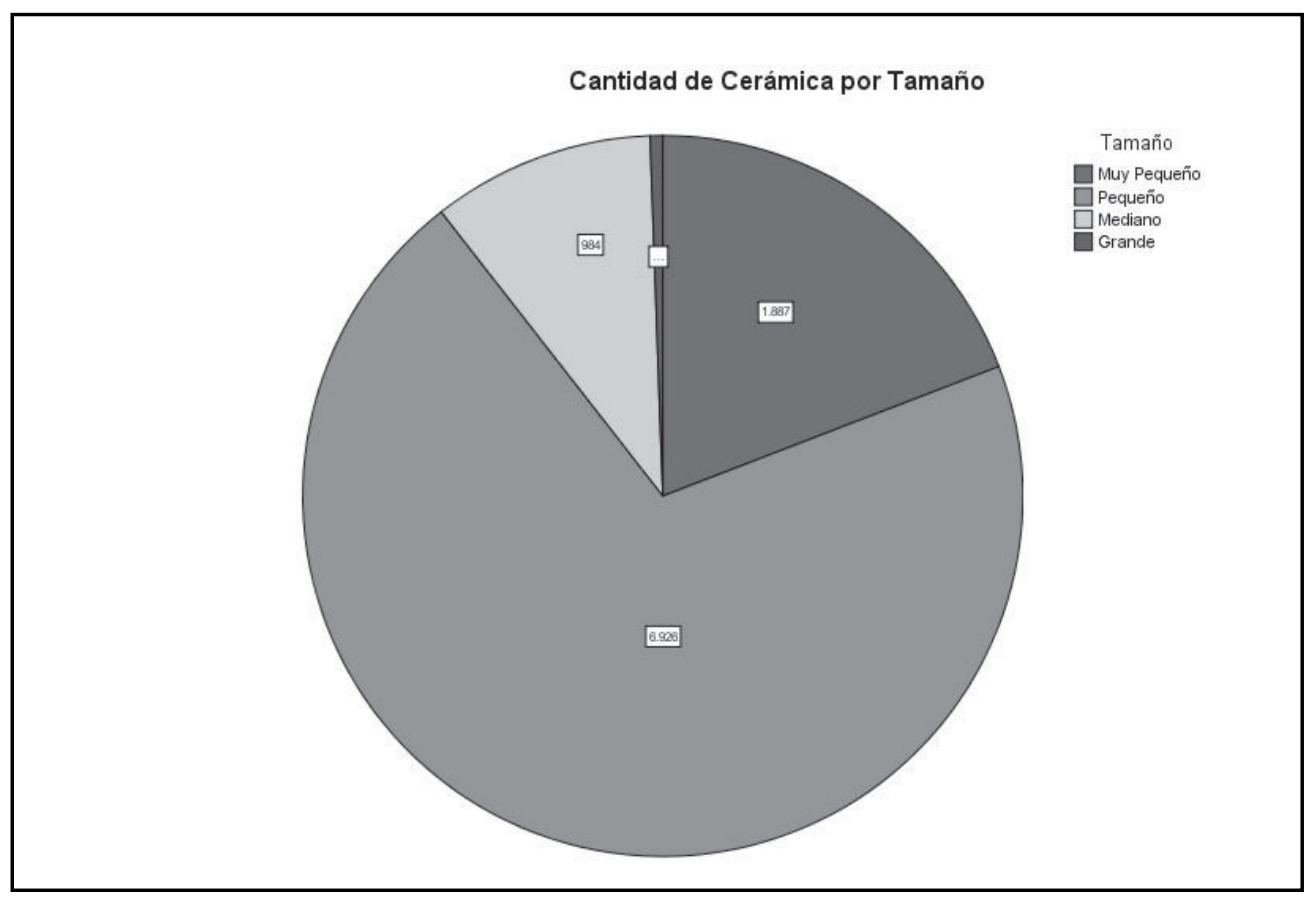

Figura 8: Distribución de los fragmentos de acuerdo al tamaño ( $\mathrm{N}=9853)$.

muestra estuvo compuesta por 9.853 fragmentos cerámicos, distribuidos entre varios estilos y tamaños. Con respecto al estilo, predomina la cerámica alisada sin decoración $(n=9.197,93 \%)$. La cerámica decorada se dividió en diversos estilos, destacándose el Cruz Vinto $(n=428,65 \%)$ seguido por el estilo Mallku ( $n=178,27 \%)$. El resto de la muestra corresponde a estilos no locales, principalmente cerámica Intersalar proveniente del Norte y cerámica Yura, originaria de los Valles del Sur; y a cerámica decorada indeterminada (Figura 7).

El agrupamiento del material relevado con respecto al tamaño se presenta en el gráfico de la Figura 8. La tendencia es muy marcada hacia los fragmentos de tamaño pequeño $(n=6.926,70 \%$ de la muestra), seguido por los tamaños muy pequeños $(n=1.887,19 \%)$ (Figura 8). Estos tamaños de clastos son muy fáciles de transportar por agentes naturales como el agua, mientras que para transportar fragmentos más grandes es necesaria la acción de la gravedad a través de pendientes más pronunciadas (Berardi 2004).

Con respecto a la cantidad de cerámica por UMD, utilizamos una escala derivada de la composición de la muestra para no realizar una división arbitraria. Las categorías que utilizamos para medir la cantidad fueron: Baja (entre 0 y 42 fragmentos), Media (43 a 121 fragmentos), Alta (122 a 337 fragmentos), y Muy Alta (más de 337 fragmentos). Estos intervalos corresponden a los percentiles en los que se divide la muestra a partir de un diagrama de cajas. 

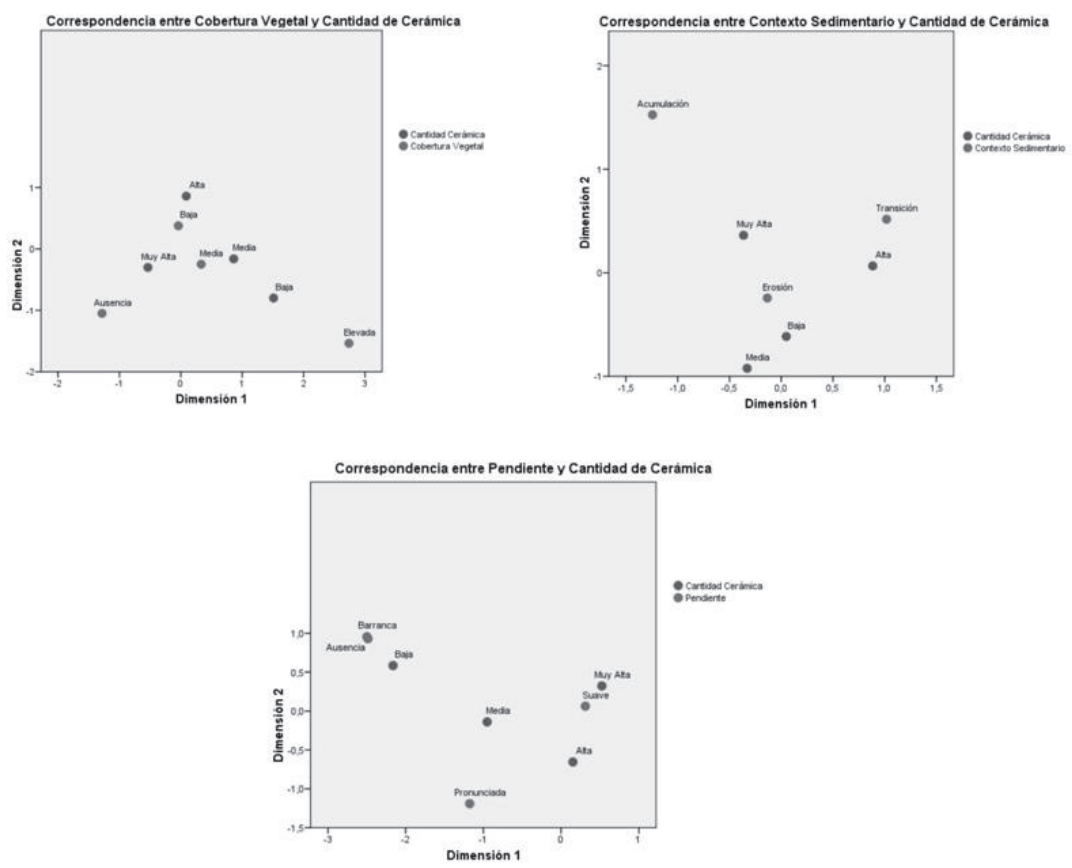

Figura 9: Gráficos de correspondencia entre cobertura vegetal y cantidad de cerámica (arriba, izquierda); contexto sedimentario y cantidad de cerámica (arriba, derecha) y pendiente y cantidad de cerámica (abajo).

\subsection{Relación entre la cantidad de cerámica y los procesos de formación}

La cantidad de cerámica por UMD fue la variable que utilizamos para evaluar la incidencia de los procesos de formación en la conformación del registro. Al integrar la cantidad, el tamaño y la distribución podemos vislumbrar cuáles de los factores descritos anteriormente estaría actuando de manera más intensa.

Para ello, realizamos un análisis de correspondencia entre las variables de integridad del registro y la cantidad de cerámica. Las tendencias fueron las mostradas en la Figura 9.

Del análisis de correspondencias surgen una serie de tendencias:

a) Cobertura Vegetal y Cantidad de Cerámica: en el gráfico (Figura 9, arriba izquierda) se observa una asociación entre la cobertura vegetal baja y la cantidad de cerámica alta. Existe también una tendencia de asociación entre la cantidad de cerámica media y cobertura vegetal media. Estas relaciones son las esperadas, ya que la cobertura vegetal condiciona la visibilidad de los fragmentos.

b) Contexto Sedimentario y Cantidad de Cerámica: se observa una tendencia entre los contextos de erosión y una cantidad baja de cerámica (Figura 9, arriba derecha). También hay una tendencia más débil entre la cantidad de cerámica media y los contextos de erosión. Las UMD con una cantidad alta de cerámica se asocian 


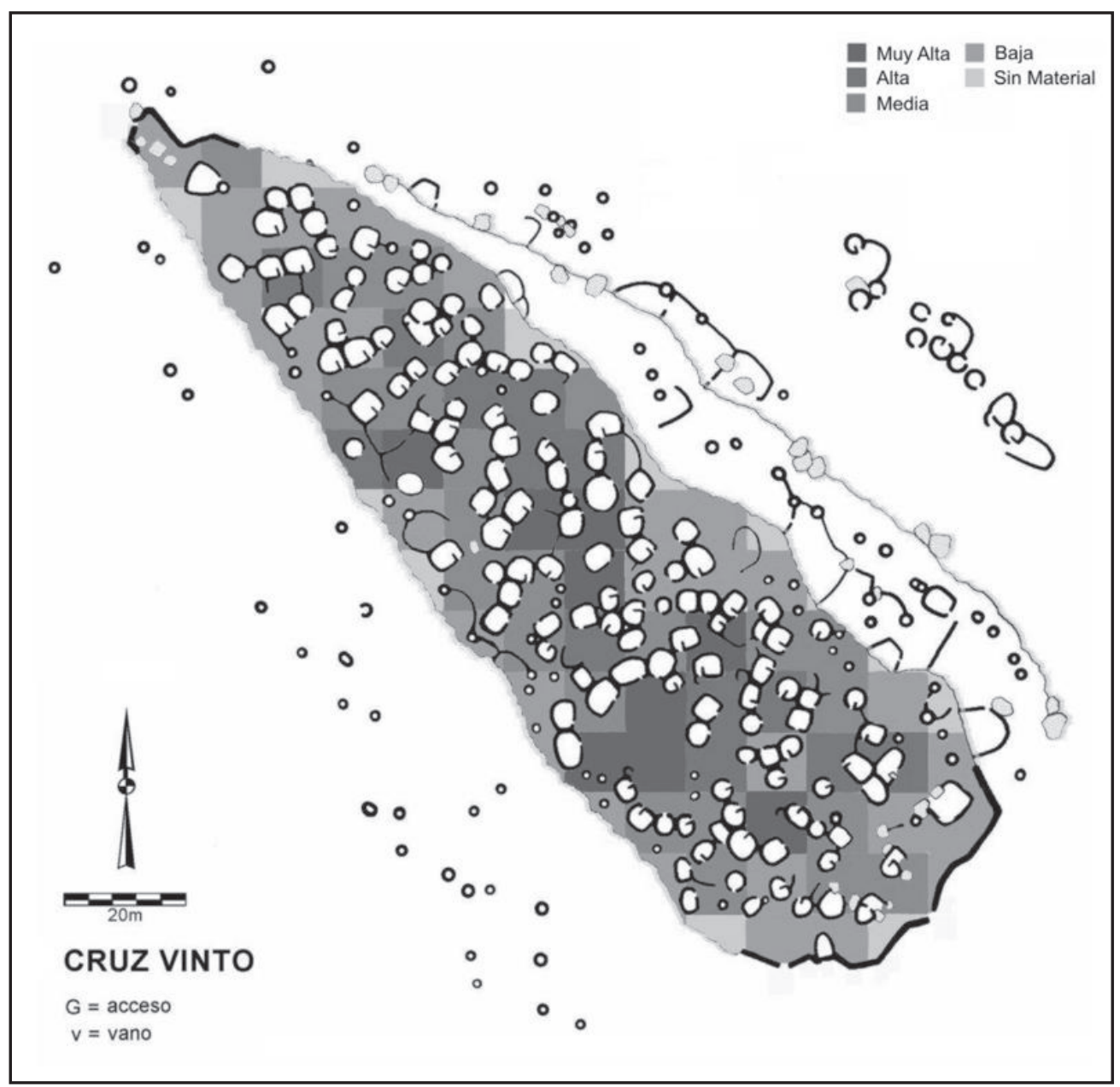

Figura 10: Cantidad de cerámica por UMD.

levemente a los contextos de transición. De todas maneras, los contextos de transición, y particularmente los de acumulación no muestran tendencias marcadas debido a que tienen muy poca representación en la muestra.

c) Pendiente y Cantidad de Cerámica: estas variables se relacionaron de acuerdo con las expectativas (Figura 9, abajo). Las UMD con cantidad baja de cerámica se asocian con las barrancas. La asociación entre ausencia de pendiente y cerámica baja no es representativa debido a que las UMD con ausencia de pendiente son muy pocas en la muestra (1\%). Por el otro lado, existe una tendencia entre las UMD con cantidad de cerámica muy alta y las pendientes suaves, y también entre las pendientes suaves y la cantidad de cerámica alta. Por lo tanto, la cantidad de cerámica depende de la pendiente. 
Figura 11: Transecto norte - sur de densidad de material. En el eje X están representados los números de UMD y en Y la cantidad de material en cada una.

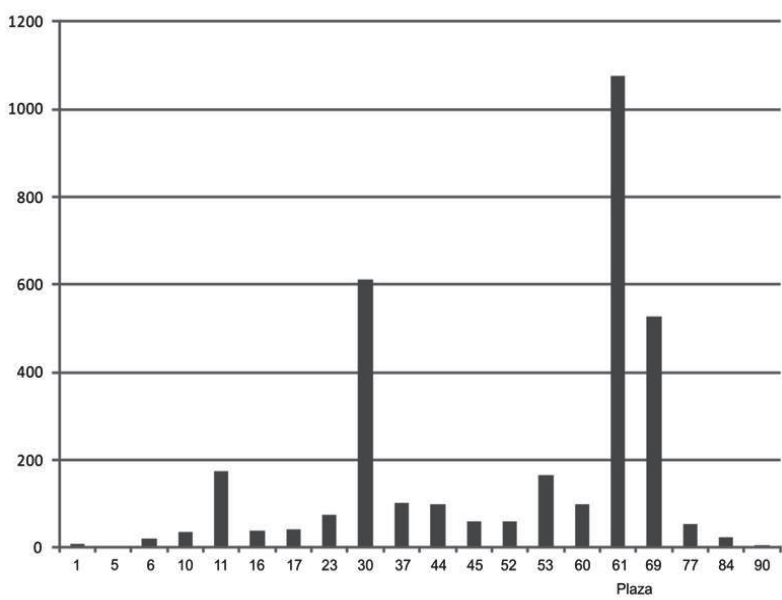

\subsection{Distribución del material cerámico}

Para evaluar la concentración de los materiales generamos un mapa temático teniendo en cuenta la cantidad de cerámica presente por UMD (Figura 10).

En este gráfico se observa que la mayor densidad de cerámica se registró hacia el centro del asentamiento, principalmente en las UMD que corresponden a la plaza y a los sectores del norte de la misma. A partir de una transecta norte-sur de las UMD que pasan por la plaza, generamos el siguiente gráfico, donde se aprecia claramente la diferencia de densidad de material de la plaza en relación con las demás (Figura 11).

Con respecto a la cerámica diagnóstica temporalmente, evaluamos la distribución espacial de dos estilos: el estilo Cruz Vinto, ubicado cronológicamente a comienzos del año 1200 DC y el estilo Mallku, característico del PDR Tardío entre el 1200 y el 1450 DC (Arellano y Berberián 1981; Nielsen 2002, 2006). En la Figura 12 vemos que no hay una concentración espacial de la cerámica diagnóstica, sino que la misma se distribuye por todo el asentamiento.

\section{Discusión}

En los apartados anteriores desarrollamos y presentamos los resultados de la metodología empleada. Vamos primero a discutir la evidencia del análisis sintáctico y luego el análisis del material de superficie, para finalmente integrar los resultados de ambos.

\subsection{Sintaxis espacial: un espacio corporativo}

A partir del análisis de las características sintácticas de Cruz Vinto podemos proponer lo siguiente: 


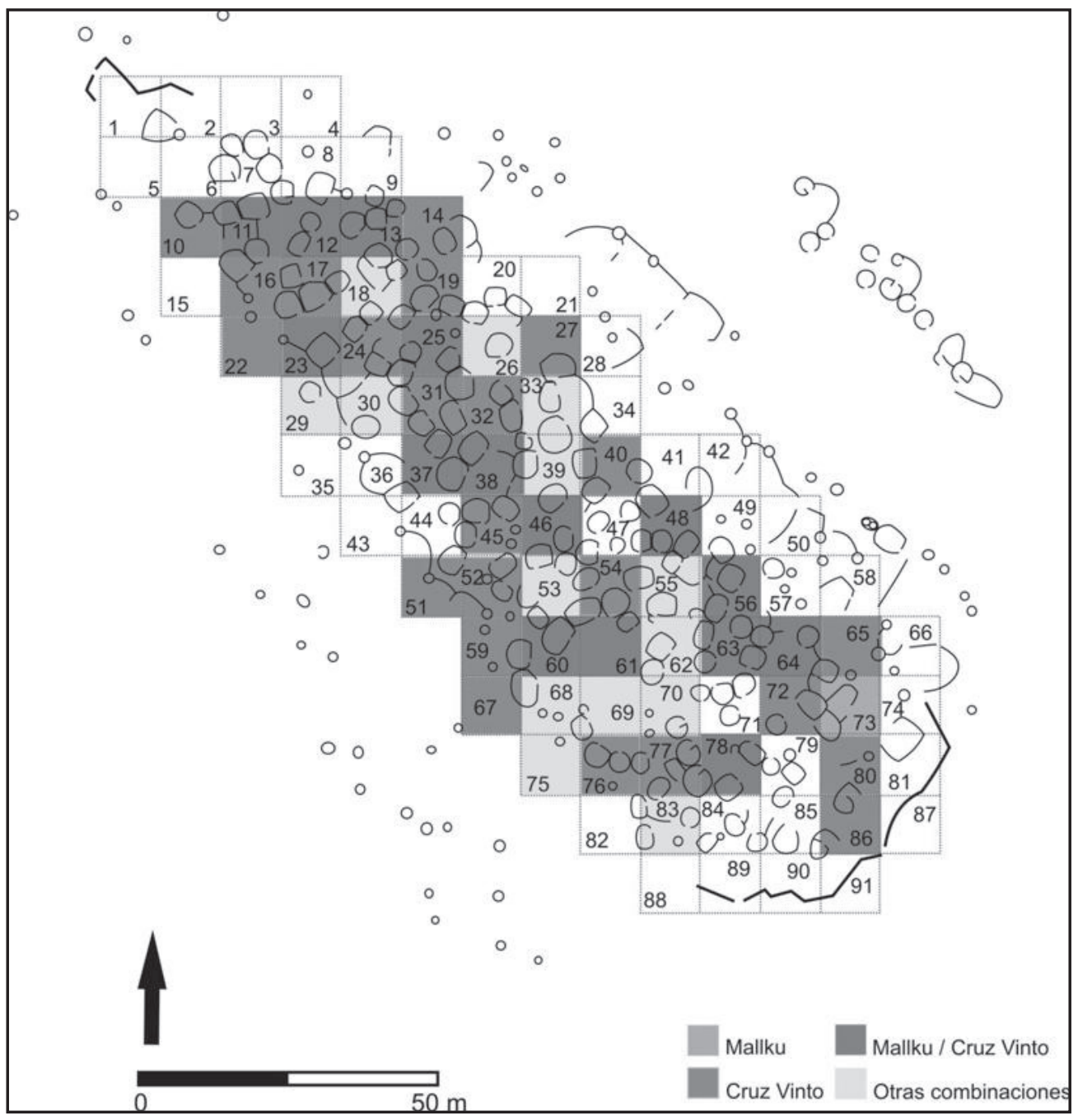

Figura 12: Dispersión de la cerámica decorada diagnóstica en el asentamiento.

La mayor cantidad de espacios convexos del asentamiento corresponde a internodos, de acuerdo con sus características sintácticas (105: 199; 53\% de la muestra). Estos espacios estarían vinculados, según el modelo propuesto, a vías de circulación con bajas probabilidades de realización de actividades. Siguen en importancia los espacios con bajo índice de unión axial y bajo índice de permeabilidad (78: 199; 39\% de la muestra). Estos espacios corresponderían, de acuerdo con el modelo, a espacios que no tienen recintos adyacentes ni se encuentran articulando vías de circulación o vías perceptivas. Finalmente, con la misma cantidad de casos, se encuentran los espacios definidos como nodos (8: 199; 4\% de la muestra) y aquellos con alta unión axial y 
alta permeabilidad (8: 199; 4\% de la muestra). La última categoría está representada principalmente por los espacios convexos que componen la plaza del asentamiento. Ya volveremos sobre la misma más adelante.

En síntesis, el modelo de análisis espacial en términos de nodos e internodos no es tan tajante como se supuso en un principio. Las funciones de circulación y actividades no son excluyentes, por lo menos en la plaza o espacio central.

La mayoría de los espacios analizados estarían destinados a la circulación, lo cual no sería coherente con un sitio de función residencial en el que se realizaron actividades al aire libre. Por otro lado, si pensamos que las funciones de circulación y actividades no son excluyentes, entonces el panorama sería de actividades realizadas en espacios de fácil percepción por los demás habitantes del asentamiento. El índice de unión axial contempla la articulación también en términos perceptivos, es decir, la cantidad de espacios convexos que pueden percibirse visualmente desde un punto.

En este sentido, el asentamiento en general presenta un alto índice de unión axial, por lo cual no existen espacios exteriores segregados a la circulación. La porción central del asentamiento presenta los mayores índices de permeabilidad, en contraste con los bordes donde hay gran cantidad de afloramientos rocosos y con la barranca. Esto sería coherente con actividades realizadas en lugares resguardados.

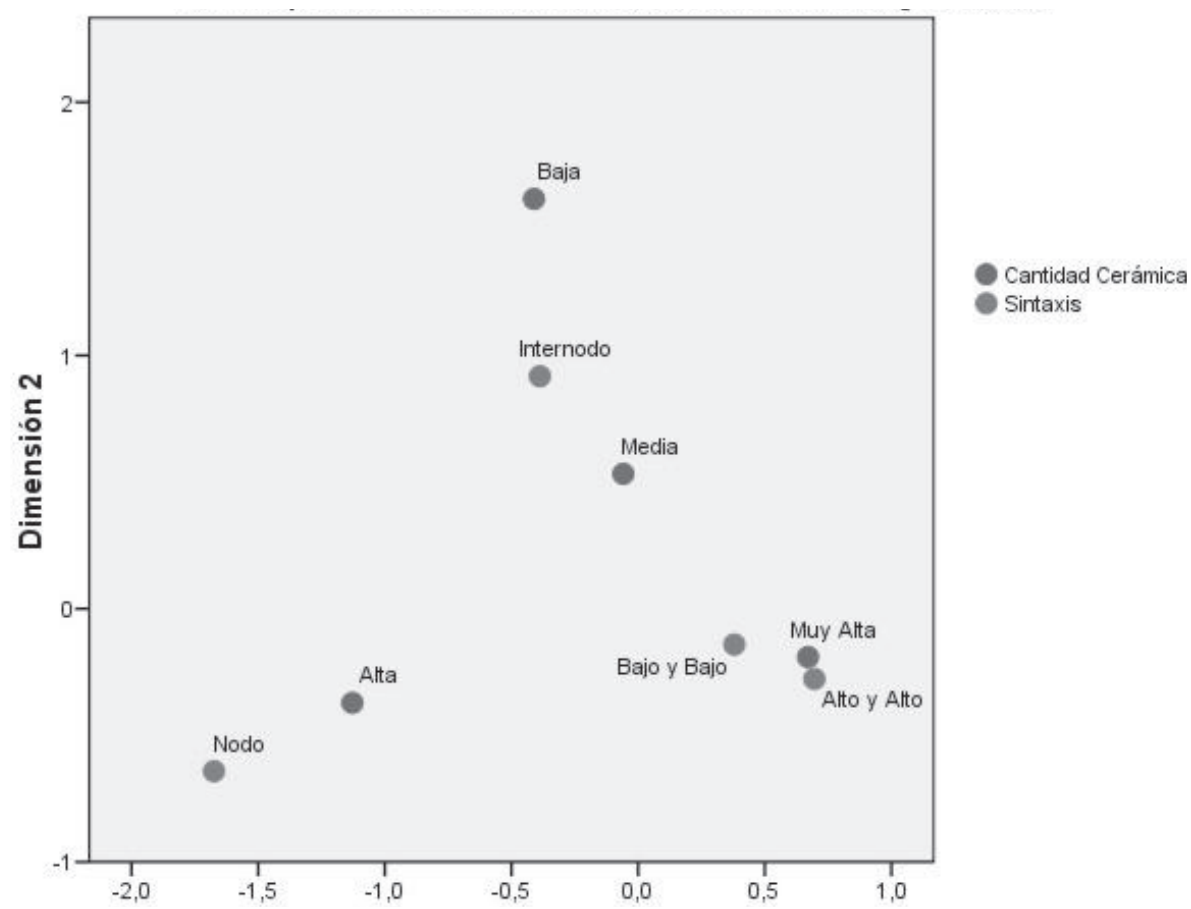

Figura 13: Comparación entre los resultados de la sintaxis espacial y la distribución de la cerámica. 
La plaza se conforma como el espacio central del asentamiento, ya que por un lado estaría articulando varias rutas de circulación intrasitio, y por el otro tiene un alto índice de recintos directamente permeables. En el resto del asentamiento, los espacios convexos con mayor grado de permeabilidad y axialidad no coinciden.

Por lo tanto, en términos del análisis espacial, a partir de los planos, podemos sostener que la organización del espacio externo en Cruz Vinto es coherente con una sociedad que no se encuentra ni dividida ni jerarquizada. Todos los espacios son accesibles tanto para la circulación como para la percepción.

\subsection{Distribución del material superficial}

El análisis de la distribución del material sumado a los procesos de formación no permite interpretar actividades en los espacios externos. El registro se encuentra muy alterado por un ambiente muy dinámico, sumado a la poca potencia de los suelos y a la preminencia de un ambiente mayormente erosivo. Los tamaños de los fragmentos nos inclinan también a pensar en esta dirección, ya que los tamaños mayoritarios son fácilmente transportables por el agua y la pendiente.

La mayoría del material se encuentra depositado en el centro del asentamiento, lo cual coincide con las zonas más protegidas del viento y con las pendientes más suaves. Las UMD con valores más altos de material se encuentran ubicadas en la plaza del sitio. Al igual que con el análisis sintáctico del espacio, la plaza es el espacio que más se destaca por la presencia de material.

\subsection{Cruz Vinto desde la superficie: relación sintaxis-material superficial}

Para relacionar los resultados de ambos análisis, generamos un gráfico de correspondencias donde las diferentes categorías de espacios convexos determinadas en el análisis sintáctico se cruzaron con la distribución de la cerámica. El resultado fue el recogido en la Figura 13.

Las tendencias que podemos observar en el gráfico (Figura 13) son las siguientes. Hay una asociación entre la cantidad de cerámica muy alta y las UMD con espacios convexos bajos y bajos; y con los espacios convexos alto y alto. La cantidad de cerámica media tiene una tendencia a asociarse con espacios convexos nodales, y una tendencia más débil con espacios convexos bajos y bajos. La cantidad de cerámica baja tiene una tendencia débil a asociarse con los espacios convexos internodales. Finalmente, la cantidad de cerámica alta se encuentra asociada a los espacios nodales (aunque este último tipo tiene una representación mínima en la muestra: 13\%), por lo que esta tendencia es relativa.

De acuerdo con el modelo planteado en la sintaxis, vemos que la distribución del material superficial no soporta las expectativas sobre los espacios nodales e internodales. De ser así, las cantidades de cerámica muy altas y altas se hubieran asociado con los espacios convexos nodales; y las cantidades baja y media a los espacios internodales. 
Del análisis del material superficial podemos interpretar la acción de los agentes naturales en la conformación del registro en Cruz Vinto. Vimos que hay una tendencia de asociación entre la cantidad de cerámica y la pendiente, una tendencia entre la cantidad de cerámica y los contextos de erosión. Estas asociaciones nos indican que el ambiente es muy dinámico, y que la distribución del material se encuentra estructurada por la acción de los agentes naturales como el agua, que actúa a través de las pendientes como agente de transporte, y también como agente erosivo de los suelos.

La situación de la plaza del asentamiento merece un comentario aparte. En este lugar coinciden las vías de circulación del asentamiento y los espacios convexos que la componen tienen un alto índice de permeabilidad y un alto índice de unión axial. También en estos espacios convexos se concentra la mayor cantidad de material del asentamiento. En este momento no es posible interpretar las prácticas llevadas a cabo en la misma, pero es notorio que tanto la sintaxis como la distribución del material superficial la señalen como un espacio destacado.

\section{Conclusiones}

Los análisis de sintaxis espacial, circulación y material superficial aportan información relevante en dos sentidos: por un lado permiten caracterizar la estructuración de los espacios externos vinculados con las unidades domésticas; y por otro resultan un paso metodológico importante a la hora de planificar las excavaciones.

Con respecto al primer punto, podemos sostener que la estructuración de los espacios exteriores de Cruz Vinto, en términos de escenarios para las prácticas cotidianas, se relaciona con un sistema de disposiciones vinculado a una experiencia de la sociedad corporativa o descentralizada. En las sociedades descentralizadas, y debido a la ausencia de instituciones centrales que eviten la fisión de las unidades constitutivas, deben estar presentes prácticas tendentes a reforzar la identidad y cohesión del grupo. Materialmente esto puede manifestarse en rituales y códigos compartidos, en la arquitectura, la vestimenta y los elementos de uso cotidiano que refuercen la experiencia de pertenencia a una misma comunidad (Nielsen 2006).

Los espacios exteriores no presentan divisiones, confluyendo en los mismos las actividades realizadas al aire libre con la circulación. Esta falta de límites físicos tiene una gran incidencia en la manera en que se experimentaban estos espacios. No solamente es posible circular libremente por el asentamiento, sino que también se perciben los sonidos y los olores y se visualiza todo lo que está pasando en el poblado. La experiencia de realizar actividades y circular por el asentamiento enfatiza la inclusión y la igualdad, es decir, la experiencia de lo corporativo. Y también es una experiencia que enfatiza la continuidad, ya que los espacios exteriores no imponen límites físicos para la circulación. Estos espacios de circulación y de actividades permiten acceder a cualquier punto del asentamiento, incluyendo la plaza (Vaquer 2009; Vaquer et al. 2010). 
Cuando cruzamos el modelo propuesto a partir de la sintaxis con el material superficial, vimos que no pudieron sostenerse las categorías propuestas en el modelo. La distribución del material superficial obedece principalmente a la acción de agentes naturales, principalmente el agua. La distribución por tamaño de los fragmentos cerámicos resultó muy ilustrativa al respecto: el $70 \%$ de la muestra correspondió a fragmentos fácilmente transportables por la acción del agua y la pendiente. No pudimos determinar la existencia de nodos e internodos a partir de la distribución del material superficial.

Este último punto es importante a la hora de interpretar los resultados de los análisis basados en la sintaxis espacial. Estos trabajos también han sido criticados debido a su orientación formalista, que tiende a homogeneizar la experiencia espacial de los habitantes de un asentamiento sin tener en cuenta variables como género o edad (Allison 1999; Mañana, Blanco y Ayán 2002; ver también Thomas 2001); y a que presentan una visión estructuralista de la organización del espacio que no tiene en cuenta a los agentes sociales y crea un espacio vacío y abstracto (Soja 1989). Además, la relación que proponen Hillier y Hanson (1984) entre la organización espacial y las relaciones espaciales es muy simplista, ya que toman la división de Durkheim entre solidaridad orgánica y solidaridad mecánica como el único modelo para explicar las relaciones sociales constituidas por las relaciones espaciales.

Por lo tanto, y en vista de lo mencionado anteriormente, no es posible considerar concluyentes las interpretaciones surgidas de la sintaxis espacial. Es necesario contrastarlas con otras líneas de evidencia como la distribución del material superficial, o mejor aún, resultados de excavaciones.

La principal ventaja de los análisis de sintaxis espacial es que permiten una primera aproximación a la estructura de los asentamientos a través de una metodología sólida y replicable. De esta manera, es posible generar un modelo espacial sin necesidad de excavaciones. Consideramos, para concluir, que para una interpretación robusta sobre la estructuración del espacio es necesario cruzar varias líneas de evidencia a diversas escalas. La sintaxis espacial en este sentido puede ser utilizada como una de las vueltas más en el «espiral hermenéutico» (Hodder 1999) de la interpretación del pasado.

\section{Referencias bibliográficas}

Allison, Penelope

1999 «Introduction», en The Archaeology of Household Activities, P. Allison, ed., pp. 1-18. Londres: Routledge.

Arellano, Jorge y Eduardo Berberián

1981 «Mallku: el señorío Post-Tiwanaku del Altiplano Sur de Bolivia (provincias de Nor y Sur Lípez - Departamento Potosí). Bulletin de l'Institut Francais d'Etudes Andines 10 (1-2): 51-84. 
BERARDI, Maximiliano

2004 Historia Ocupacional de Los Amarillos (Quebrada de Yacoraite, Jujuy). Análisis del material arqueológico en superficie mediante SIG. Tesis de Licenciatura. Universidad de Buenos Aires.

Bourdieu, Pierre

1977 Outline of a Theory of Practice. Cambridge: Cambridge University Press.

1999a Meditaciones pascalianas. Barcelona: Anagrama.

1999b The Logic of Practice. Londres: Routledge.

2000 La dominación masculina. Barcelona: Anagrama.

Foucault, Michel

1975 Vigilar y Castigar. Nacimiento de la Prisión. Buenos Aires: Siglo XXI.

HiLlier, Bill y Julienne HANSON

1984 The Social Logic of Space. Cambridge: Cambridge University Press.

HODDER, Ian

1999 The Archaeological Process. An Introduction. Londres: Blackwell.

INGOLD, Tim

2000 The Perception of the Environment. Essays on Livelihood, Dwelling and Skills. Londres: Routledge.

Mañana BorrazÁs, Patricia, Rebeca Blanco Rotea y Xurxo Ayán Vila

2002 Arqueotectura 1: bases teórico metodológicas para una arqueología de la arquitectura. TAPA, 25. Santiago de Compostela: Universidade de Santiago de Compostela.

Nielsen, Axel E.

1998 «Tendencias de larga duración en la ocupación humana del Altiplano de Lípez (Potosí, Bolivia)», en Los desarrollos locales y sus territorios, B. Cremonte, comp., pp. 65-102. Universidad Nacional de Jujuy.

2000 Andean Caravans. An Etnoarchaeology. Tesis doctoral, Universidad de Arizona.

2001 «Evolución del espacio doméstico en el Norte de Lípez, Bolivia (Potosí, Bolivia): ca. 900 -1700 DC». Estudios Atacameños 21: 41-61.

2002 «Asentamientos, conflictos y cambio social en el Altiplano de Lípez (Potosí)». Revista Española de Antropología Americana 32: 179-205.

2006 «Plazas para los antepasados: descentralización y poder corporativo en las formaciones sociales preincaicas de los Andes circumpuneños». Estudios Atacameños 3: 63-89.

Nielsen, Axel E., María Vázquez, Julio Avalos y Carlos Angiorama

1999 «Prospecciones arqueológicas en la Reserva «Eduardo Avaroa» (Sud Lípez, Depto. Potosí, Bolivia)». Relaciones de la Sociedad Argentina de Antropología 24: 95-124.

Soja, Edward

1989 Postmodern Geographies. The Reassertion of Space in Critical Social Theory. Londres: Verso.

Thomas, Julian

1996 Time, Culture and Identity. Londres: Routledge.

2001 «Archaeologies of Place and Landscape», en Archaeological Theory Today, I. Hodder, ed., pp. 165-186. Cambridge: Polity Press. 
VAquer, José M.

2009 «Análisis de planos como primer etapa de un proyecto de investigación. Un ejemplo de Cruz Vinto (Norte de Lípez, Bolivia) durante el Periodo de Desarrollos Regionales Tardío (ca. 1200-1430 AD)», en Entre pasados y presentes II. Estudios contemporáneos en Ciencias Antropológicas, T. Bourlot et al., eds., pp. 425-442. Buenos Aires: Fundación Azara.

Vaquer, José M., Eva CAlomino y Verónica Zuccarelli

2010 «Habitando Cruz Vinto: temporalidad y espacialidad en un pukara del Periodo de Desarrollos Regionales Tardío (1200-1450 DC) en el Norte de Lípez (Potosí, Bolivia)». Arqueología 16: 13-33. 